\title{
Servir al Estado, servir al poder: la burocracia en el proceso de construcción estatal en América Latina
}

Serve the Power, Serve the State: Bureaucracy and State Building in Latin America

\author{
Juan Carlos Garavaglia \\ Profesor ICREA en la Universitat \\ Pompeu Fabra (UFP - Barcelona) \\ e-mail: jcgara@hotmail.com
}

\section{Resumen}

Este trabajo es un estudio sobre las relaciones entre el proceso de construcción estatal y el desarrollo de la burocracia en América Latina desde fines del periodo colonial hasta los primeros cincuenta años posteriores a la independencia. Analizamos aquí los datos resultantes de nuestro proyecto de investigación sostenido por el ERC sobre los casos de Guatemala, Costa Rica, Colombia, Ecuador, Chile, Argentina y Uruguay. Nos hallamos ante una realidad compleja en cuanto al funcionamiento de la burocracia estatal y de aquellos agentes que, sin percibir sueldos estatales, tienen sin embargo funciones relacionadas con la administración estatal en áreas como la justicia o la percepción de impuestos. El trabajo analiza sobre todo, los datos referidos al estado central, con la excepción de la provincia de Santa Fe en la Argentina que ha sido incluida.

\section{Resumo}

Este trabalho é um estudo sobre as relações entre o processo de construção estatal e o desenvolvimento da burocracia na América latina desde o final do período colonial até os primeiros cinquenta anos posteriores à Independência. Analisamos aqui os dados que resultaram de nosso projeto de pesquisa apoiado pelo European Research Council sobre os casos da Guatemala, Costa Rica, Colômbia, Equador, Chile, Argentina e Uruguai. Estes dados demonstram que estamos diante de uma realidade complexa no que toca ao funcionamento da burocracia estatal e de agentes que, apesar de não receberem salários do Estado, possuíam funções relacionadas com a administração estatal em áreas como a da justiça e a da arrecadação de impostos. Este trabalho analisa, sobretudo, os dados referentes ao Estado central, com exceção da Província de Santa Fé que também foi incluída.

\section{Abstract \\ This study focuses on the relations between the process of State-Building and the development of bureaucracy in Latin America from the end of the colonial period until the first fifty years after independence. In it, we will examine data about the cases of Guatemala, Costa Rica, Colombia, Equator, Chile, Argentina and Uruguay, which were gathered during our research project sponsored by the European Research Council. This information demonstrates that we are facing a complex reality as regards the functioning of the State's bureaucracy and those agents that, even if they do not receive salaries from the state, have functions that are related to its administration in areas such as justice or tax collecting. The work}


will analyze above all the data that concern the central state, except for the province of Santa Fe in Argentina that has also been included.

\section{Palabras-chave}

América Latina, construcción estatal, burocracia, servidores del poder, funcionarios del Estado

\section{Palavras-chave}

América latina, construção estatal, burocracia, servidores do poder, funcionários do Estado

\section{Keywords}

Latin America, State Building, bureaucracy, civil servants, state employers 
GARAVAGLIA, Juan Carlos. Algunos aspectos preliminares acerca de la 'transición fiscal' en América Latina: 1800-1850. Illes i Imperis, n.13, 2010.

2

El desarrollo de la investigación y sus publicaciones en http://www.statebglat.upf.edu

3

Esta Audiencia tuvo una etapa precedente en la que era itinerante, es decir, la seguía al Monarca en sus desplazamientos.

4

WEBER, Max. Economía y sociedad. México: Fondo de Cultura Económica, 1986.

5 BURKHOLDER, Mark A. y CHANDLER, Dewitt Samuel. De la impotencia a la autoridad: la Corona española y las Audiencias en América, 1687-1808. México: Fondo de Cultura Económica, 1984

6

LÓPEZ TAVERNE, Elvira. "La configuración de un cuerpo burocrático en el marco del proceso de construcción estatal. Chile 1810-1860", 2011, mss.

\section{Introducción}

Este trabajo forma parte de la investigación State Building in Latin América y constituye en realidad, lo que podriamos considerar el segundo tramo de ese proyecto. Después de haber estudiado los fundamentos de la fiscalidad durante los primeros cinco decenios de vida independiente ${ }^{1} y$ antes de comenzar los dos tramos siguientes, que estarán centrados en el fenómeno del ejercicio de la violencia y el estudio de los ordenamientos de justicia, analizaremos en esta ocasión algunos aspectos fundamentales de la historia de la burocracia y de la administración desde fines del periodo colonial hasta los años sesenta y setenta del siglo XIX, límite más o menos preciso que nos hemos fijado para este proyecto. El artículo se refiere especialmente a los casos de Guatemala, Costa Rica, Colombia, Ecuador, Chile, Argentina y Uruguay que son los tratados por la investigación financiada por el European Research Councir.

\section{2. ¿Cómo se sirve a un Imperio?}

Si bien nuestro esfuerzo principal está abocado al proceso de construcción estatal durante el siglo XIX, es imposible comenzar el estudio de esta cuestión sin referirse al tipo de administración que encontrarán aquellos que conducirán el proceso de la revolución de independencia a partir de la primera década de ese siglo. Sobre todo en el caso de la experiencia colonial enmarcada bajo el dominio del sistema imperial hispano, que tuvo en la administración uno de sus pilares más sobresalientes. Ya desde los primeros decenios del siglo XVI, la Corona fue poniendo los hitos de un sistema administrativo y judicial que se inaugura con la fundación de la primera Audiencia americana en Santo Domingo en 1511. Este alto tribunal es el cuarto en todo el espacio dominado por la Corona de Castilla a ambos lados del océano (le preceden la Chancillería de Valladolid en $1475^{3}$, la Galicia en 1480/1484 y la de Ciudad Real en 1494, trasladada después en 1505 a Granada). Es decir, la extensión a América del entramado judicial castellano se realizó muy tempranamente. A fines del siglo XVIII, existen trece Audiencias en todo el espacio americano y es en ellas donde primero se advierten en América no pocos de los elementos de una auténtica carrera burocrática tal como los definió Max Weber ${ }^{4}$, por supuesto, hubo variados momentos en cuanto a la burocratización de las carreras en este recorrido de las Audiencias y un estudio pionero lo dejó ver ya hace tiempo ${ }^{5}$, pero lo que nos interesa aquí es mostrar el carácter de "modelo" de esa institución judicial en cuanto al tema que nos preocupa. Desde los años ochenta del siglo XVIII, estos verdaderos funcionarios, justamente por ser más próximos al modelo weberiano (es decir, contar con un grado profesional habilitante, haber seguido un carrera con sucesivos ascensos, poseer un gran respeto por su función en el marco del Imperio - fuera cual fuera su lugar de ejercerla - y además, haber anudado menos relaciones con las familias de los notables locales), serán los primeros en partir o ser desterrados en el momento de la ruptura independentista. Poco los ataba a esa u otra ciudad, en donde con frecuencia se sentían de paso y mucho los unía en su juramento de fidelidad a la Corona. Lo ocurrido con ellos en Quito, Santafé de Bogotá, Santiago de Chile y en Buenos Aires, con diversas alternativas, es un ejemplo claro de lo que decimos, pues por una razón u otra, y salvo alguna excepción muy puntual en Chile ${ }^{6}$, fiscales y oidores de las Audiencias desaparecen muy rápido de escena. En otros casos, como en Guatemala, los oidores se dividen en su opinión frente a la ruptura 
O'DONNELL, Guillermo A. La poliarquias y la (in)efectividad de la ley en América Latina. In: Idem. Disonancias. Críticas democráticas a la democracia: Buenos Aires, Prometeo, 2007.

8

KAMEN, Henry. Una sociedad conflictiva: España, 1469-1714. Madrid: Alianza Editorial, 1989. (y aquellos con fuertes vínculos locales, siguen su carrera judicial en las nuevas configuraciones estatales). No olvidemos que las Audiencias podian tener funciones de gobierno - suplantaban al virrey o al capitán general en su ausencia - y además, era obvio que la construcción de un proyecto estatal independiente y enfrentado a la Corona, no podía dejar en manos de los altos funcionarios fieles al Rey un instrumento tan poderoso como era el del pináculo del sistema judicial. Este es un elemento fundamental en toda tarea de gobierno en vistas a la construcción de lo que Guillermo 0 'Donnell ha llamado el "estatuto legal" del Estado. ${ }^{7}$

Mas, recordemos que la verdadera cúspide del poder político estaba a cargo de los virreyes y los primeros son nombrados en América después de la instauración de las dos Audiencias iniciales (Santo Domingo, 1511 y Nueva España, 1528), siendo el Perú y la Nueva España, los lugares en donde hubo virreyes desde la tercera y cuarta década del siglo XVI; no pocos de los primeros virreyes, como Toledo y Velasco, lo fueron sucesivamente en ambos virreinatos y en algunos casos, hubo virreyes que habian ya ocupados funciones similares en Galicia, Aragón o en Italia. En los primeros 150 años del dominio colonial, era normal que los virreyes pertenecieran a las familias de la nobleza y en algunos casos, a la alta nobleza, como los Mendoza, los Alburquerque, los Mancera o los Manríquez. Pero, tomemos un ejemplo, casi al azar. En 1680 fue nombrado vigésimo sexto virrey de la Nueva España, don Tomás Antonio de la Cerda y Aragón, tercer marqués de la Laguna. Este no sólo era el hermano menor del poderosísimo octavo duque de Medinaceli (miembro de la alta nobleza, es decir, los "Grandes") valido en ese entonces de Carlos II y tronco de una familia que pretendía remontar hasta Alfonso el Sabio y San Luís de Francia, sino que había esposado a la condesa de Paredes, doña Maria Luisa Manrique de Lara y Gonzaga, hija de Vespasiano Gonzaga, de Mantua y de Maria Inés Manrique de Lara, de la casa de los Manrique, descendiente por lo tanto ella también de una de las familias mas viejas y poderosas de la nobleza castellana. Pero, ello no fue óbice para que el marqués desempeñara una carrera militar y burocrática como Capitán General en Andalucía y miembro del Consejo de Indias, antes de llegar, por influencia de su poderoso hermano, a ser virrey de la Nueva España. No debemos asombrarnos por este hecho: según un especialista del siglo XVII español ${ }^{8}$, España era en esa época el país europeo en donde la aristocracia ocupaba el rol más importante en el manejo del estado y en la sociedad en general.

Durante el periodo colonial, con frecuencia - en México, ocurre al menos en cinco oportunidades durante el siglo XVII y en el Perú en una en ese mismo siglo y en tres ocasiones hasta mediados del siglo siguiente - los obispos ocupan simultáneamente el cargo de virrey (por muerte 0 incapacidad del predecesor y en algunos casos, este interinato puede durar largos años, como cuando fray Payo Enríquez de Rivera reemplazó al virrey fallecido de México, el sexto duque de Veragua, entre 1673 y 1680). En el Perú, entre 1710 y 1716, se suceden dos arzobispos en la conducción virreinal. E incluso en un virreinato "tardío" como el de la Nueva Granada (1734) se da este mismo fenómeno.

En este sentido, la carrera de Pedro Moya de Contreras es notable. Nace, alrededor de los años veinte del siglo XVI, en una pequeña villa de Andalucia. Entra desde muy pequeño - como paje - al servicio del licenciado Juan de Ovando, en ese entonces, poderoso personaje de la corte y Presidente del Consejo de Indias. Gozando de los favores de Ovando realiza 
su carrera en la universidad de Salamanca, recibiéndose de doctor en ambos derechos. Pasa sucesivamente por un puesto menor en la catedral de Canarias, es después inquisidor en Murcia y en 1571 es enviado como organizador del tribunal de la Inquisición en México. Se ordena sacerdote en esa ciudad y en 1573 es nombrado arzobispo de la diócesis. Durante los años 1583/85, ocupó también el cargo de virrey, por la vacancia ocurrida tras la muerte del Conde de la Coruña. Fue visitador general de toda la Nueva España y al volver a la península ocupó un cargo en el Consejo de Indias y finalizó su larga carrera como Presidente de ese Consejo. Obviamente, esta es una trayectoria de excepción, pero, nos muestra una vez más la trama intrincada que unía a la Iglesia con el poder civil y la dificultad que hay en realidad al intentar separar muy taxativamente ambos aspectos del poder del estado imperial en las Indias durante los siglos XVI y XVII.

No menos sorprendente, en apariencia, es la trayectoria de quien es nombrado en 1630 arzobispo de Lima, don Fernando de Arias Ugarte. Nace en Santa Fe de Bogotá, en el seno de una familia de la elite. Hace sus estudios en Salamanca y Lérida en España. Vuelto a América, es oidor de las Audiencias de Panamá, Charcas y Lima, haciendo hasta ese momento una carrera de togado bastante típica. Pero, más tarde, se ordena sacerdote y ocupa sucesivamente las mitras de Quito, Santa Fe, Charcas y Lima. Nuevamente, vemos un complejo itinerario doble, civil y eclesiástico. Por supuesto, esto también ocurre durante esos siglos en la Península, pues desde la existencia misma de la primera Audiencia castellana, aún en su etapa itinerante, los oidores eran tanto eclesiásticos como letrados. Tomemos el ejemplo de Pedro Manso, quien muere en Madrid en 1610 como patriarca de las Indias Occidentales. Realizó estudios en la universidad de Salamanca, fue provisor de su tío el obispo de Calahorra, como asimismo, arcediano de Bilbao; siendo después oidor de la Audiencia de Pamplona, de la Chancillería de Granada, alcalde de corte, presidente de la Real Audiencia de Valladolid y finaliza su carrera como presidente del Consejo de Castilla. No hay que olvidar que las Audiencias y los virreinatos de todo el Imperio hispano están englobados en lo que ha sido llamado, con razón, "una monarquía dentro de la Iglesia".

Ya desde el siglo XVIII, en los nuevos virreinatos, como la Nueva Granada (1734) y el Río de la Plata (1776), vemos surgir la figura del virrey "funcionario", generalmente hijodalgo "de capa y espada", pero que ha tenido una larga carrera militar y burocrática de sucesivos ascensos en España y América, ya fuera como gobernador, presidente de Audiencia o capitán general, para después ser nombrado virrey. Podemos mostrar algunos ejemplos de esos itinerarios. Nicolás de Arredondo, nace en 1726, militar, participó en guerras en Italia, Gibraltar y Menorca. En 1780 pasa a América, ocupando cargos en Florida y Cuba como gobernador. En 1787 es gobernador intendente en el Río de la Plata y en 1789 reemplaza al Marqués de Loreto como virrey, ocupando esa función hasta 1795. Vuelve a España, donde será sucesivamente Capitán General de Navarra y más tarde, de Valencia y Murcia, donde ejercerá también como presidente de la Audiencia. Joaquín del Pino, gobernador de Montevideo de 1776 a 1790, presidió después la Audiencia de Chile y en 1795 ocupó la presidencia de la Audiencia de Charcas en el Alto Perú, volviendo a Chile como gobernador. En 1800 fue nombrado virrey del Río de la Plata. También, podía ocurrir que pasaran, ya teniendo el titulo de virreyes, de un virreinato al otro, como lo hizo Manuel Antonio Flores de la Nueva Granada a México en 
Esto, como ya fue dicho, había sido bastante habitual en los primeros tiempos de la colonización entre los virreinatos de la Nueva España y el Perú.

10

WEBER, Max. Op. Cit.

11

Archivo General de Simancas, (en adelante AGS), SGU (Secretaria de Guerra), Legajo 6933.7.

12

Todas las citas puntuales y las referencias al caso de Gaspar Lozano han sido tomadas de Archivo General de Indias, Sevilla, (en adelante AGI), Audiencia de Buenos Aires, 28.

13

En la lista que presenta el mejor tratado general sobre la cuestión desde el punto de vista legal, no se incluyen los Oficiales de la Real Hacienda entre los que tienen vetado ese tipo de relaciones, consultar MARILUZ URQUIJO, José. El agente de la administración pública en Indias. Buenos Aires: Instituto de Investigaciones de Historia del Derecho, 1998. p.344-350. los años ochenta. ${ }^{9}$ Este tipo de carreras, a la vez militares y burocráticas, muestran bien que cerca están estos dos ámbitos en los estudios sobre el tema y de hecho Max Weber asi lo entendió en sus trabajos ${ }^{10}$; hay aquí algo que nos parece evidente: las funciones de orden, disciplina, jerarquía y obediencia, arquetipos del comportamiento militar, no están nada alejadas de cuestiones centrales para la historia de la burocracia.

Parece innecesario señalar que estos altos funcionarios que son los virreyes desaparecen de la escena después de la Independencia, con frecuencia junto con los miembros de las Audiencias, pero no era totalmente insólito que algunos ex virreyes y algunos ex altos funcionarios hubiesen seguido viviendo en el lugar en donde tenian ya familia y una red social en la que ampararse (por ejemplo, una hija del virrey rioplatense Joaquín del Pino casó con Bernardino Rivadavia, político relevante en la Buenos Aires de la independencia y el ex regente Gutiérrez de Piñeres dejó una extensa familia en la Nueva Granada).

Pero, los derroteros complejos de una carrera de servidor de la Corona, también podían darse a niveles más bajos que los de oidores y virreyes, como veremos seguidamente. E incluso, podía alcanzar a personajes secundarios con itinerarios realmente extensos, como es, por tomar un ejemplo entre muchos, el caso de Bernardo de Veyra. Este vecino de Sonsonate presenta en 1782 un pedido de confirmación de sus antecedentes: había sido oficial pagador de los trabajadores en los sitios de Tortona y Plasencia en el Milanesado durante las guerras de Italia entre 1740 y 1748, durante de la Guerra de Sucesión Austriaca, posteriormente sirvió en el Hospital de la Pasión en Madrid, como oficial de la Real Hacienda y pasa después a América con el puesto de Alcalde Mayor a la provincia de Sonsonate, siendo con posterioridad nombrado coronel de milicias del batallón de Nicaragua". He aqui, en un personaje de nivel muy medio, una carrera al servicio del Imperio durante más de cuarenta años. Pero, veamos más de cerca, el tema de las carreras burocráticas.

\section{Carreras y redes familiares}

Cuando en agosto de 1804, Gaspar Lozano, Ministro Contador de las Cajas Principales de la Gobernación Intendencia de Córdoba del Tucumán, "solicita recaiga dho. Empleo en su hijo D. Narciso Lozano y Goyechea"12, llevaba ya a sus espaldas una carrera realmente excepcional en cuanto a su longevidad: 52 años al servicio de la Corona en siete ciudades del vasto Imperio hispano, desde Cádiz a Córdoba, pasando por Buenos Aires, Lima, Jujuy, Chuquisaca (Charcas) y Mendoza [ver cuadro 1]. Una parte relevante de esta carrera transcurre en San Salvador de Jujuy, en donde Gaspar esposó a María Teresa de Goyechea, miembro de una de las familias principales y más poderosas de la ciudad desde la época que don Martín de Goyechea había llegado de Navarra a Jujuy, en los años setenta del siglo XVII (y señalemos que Lozano, originario de Pamplona, era también navarro).

Vemos aquí un ejemplo de un hecho que se repite hasta el cansancio en las carreras burocráticas de los peninsulares en América durante la época colonial, es decir, enlazar con una familia destacada de la localidad en donde prestan su servicio (la ley lo prohibía taxativamente en el caso de los miembros de la Audiencia y otros altos funcionarios ${ }^{13}$, pese a lo cual, con cierta frecuencia, incluso en esos casos, esa limitación jurídica era pasada por alto como lo mostraron Burkholder y Chandler, 1984). Las razones de este hecho son más que obvias, pues le permiten a ambos polos de esa 
relación, ventajas evidentes y muestran en forma clara, los límites concretos de un auténtico proceso de burocratización "racional" en el Imperio hispano. Esto, por supuesto, no es para extrañarse dada la relevancia que tienen en esa sociedad las redes parentales en el proceso de constitución de los mecanismos de poder.

Cuadro 1: la foja de servicios de Gaspar Lozano, 1752-1805

\begin{tabular}{|l|l|l|}
\hline fecha & Cargo & lugar \\
\hline $14 / 1 / 1752$ & Oficial de la Secretaria de Gobierno & Cádiz \\
\hline $5 / 11 / 1756$ & Oficial de la Secretaria de Gobierno & Buenos Aires \\
\hline $13 / 7 / 1759$ & Contador del Tribunal de Cuentas & Lima \\
\hline $3 / 2 / 1761$ & Oficial Real Contador & Jujuy \\
\hline $27 / 12 / 1778$ & Oficial Real Contador & Chuquisaca \\
\hline $20 / 4 / 1780$ & Oficial Real Contador & Mendoza \\
\hline $22 / 11 / 1784$ & Ministro Contador de las Cajas Principales & Córdoba \\
\hline
\end{tabular}

Fuente: AGI-Buenos Aires, 28

Gaspar Lozano, como dijimos, pide que su hijo, Narciso, lo suceda en el cargo, dado que a su avanzada edad - le suponemos más de setenta años en 1804 - se encuentra ya hace tiempo en las puertas de la jubilación, proponiendo dividir su sueldo entre su hijo y el mismo, para que después de su muerte (que ocurre un año más tarde, en junio de 1805), Narciso gozara del entero emolumento. $Y$ asi será, pues por una solicitud firmada en Madrid en abril de 1806, sabemos que ha sido ya nombrado como Oficial Contador de las Cajas Reales de Córdoba. Narciso Lozano había esposado en Jujuy a María Teresa de Zamalloa, hija de Miguel Gregorio de Zamalloa, perteneciente a una familia de funcionarios de origen vizcaí-

14

Miguel Gregorio de Zamalloa es asesor del gobierno de Montevideo en 1802, tiene también a sus espaldas una buena carrera burocrática, ver el impreso de su relación de méritos en AGI-Charcas, 28.

15

En 1790, en un informe sobre varios aspirantes el cargo de Oficial tercero de la Contaduría General de Buenos Aires, se elije un aspirante que posee mayor antigüedad en detrimento del Oficial cuarto, AGI-Buenos Aires, 28, ver asi mismo, MARILUZ UROUIJO, José. Op. Cit., p.213-243. no ${ }^{14}$. Otro hijo de Gaspar, Juan Manuel había sido también presentado por su padre - al menos en dos ocasiones, en 1787 y 1804 - a un cargo en las oficinas de hacienda de Córdoba; en la solicitud de 1804, el padre habla de la gran experiencia del hijo "por haverme acompañado y servido a mi lado 14 años en calidad de oficial meritorio"; no sabemos si esta solicitud finalmente tuvo éxito, solo señalemos que Juan Manuel esposará a Antonia de Azcuénaga y Basavilbaso, perteneciente a un extendida red familiar de burócratas coloniales y post coloniales, hija de Miguel de Azcuénaga, vástago de otra familia vizcaína.

Varias son las enseñanzas que nos deja este ejemplo de la segunda mitad del siglo XVIII. Ante todo, Gaspar Lozano tiene una carrera burocrática "típica", siguiendo una serie de ascensos sucesivos en puestos ordenados jerárquicamente y en donde se respeta en general el criterio de antigüedad ${ }^{15}$. Pero, esta carrera no le impide saber manejarse con habilidad en un mundo en el cual las redes familiares y sociales se hallan en el centro de las relaciones de poder, al igual que, por otra parte, harán sus hijos. En este caso, es claro que los Lozano se mueven como peces en el agua en los ambientes de origen vasco navarro del Río de la Plata. Y finalmente, no solo su hijo mayor, Juan Manuel, ha trabaja- 
Ver, por ejemplo, el memorial impreso del abogado Manuel Dionisio de Velazco, hijo del Oidor Decano de la Audiencia porteña en 1799, en AGI-Buenos Aires, 28. También, en AGI-Buenos Aires, 27, Juan Manuel Alcalá García Ríos y Rojo, aspirante a un puesto en Indias recuerda "que sus Padres, Abuelos y Tíos se han dedicado en todo tiempo al RI. Servicio". MARILUZ URQUIJO, José. Op. Cit.,p.49-56, señala que esto era moneda corriente en el mundo hispano ya desde el siglo XVII.

17

Ver, para el Río de la Plata a fines del XVIII, varios ejemplos en AGI-Buenos Aires, 27.

18

AGS, SGU, legajo 6933, 34.

19

La distinción entre "venta" y "beneficio" es clara, en el primer caso, el cargo para a ser patrimonio del comprador, en el segundo, solo se adquiere el desempeño del mismo en forma temporal. ANDÚJAR, Francisco. "La venalidad de cargos y honores en España y América en el siglo XVIII", 2011, mss.

20

Ibidem.

21

Archivo Histórico Nacional, Madrid, (en adelante AHN), Consejos, 20.395, expediente 2.

22

En este caso, el oficio se remataba desde su creación en 1659, ver ARAUJO, José Joaquín de [1803]. Guía de Forasteros del Virreinato de Buenos Aires... Buenos Aires: Junta de Historia y Numismática Americana, 1908. p.396.

23

BURKHOLDER, Mark A. y CHANDLER, Dewitt Samuel. Op. Cit., p.29-118

24

Pablo de Aoíz fue muy cercano al poderoso grupo que rodeó al gobernador Bruno Mauricio de Zavala, gobernador de Buenos Aires (1717-1734), perteneciente a una familia con larga tradición burocrática y de servicio en Indias, cf. TARRAGÓ, Griselda. Las venas de la monarquía. Redes sociales, circulación de recursos y configuraciones territoriales. El Río de la Plata en el siglo XVIII. In: IMIZZCOZ BEUNZA José María y OLIVERI KORTA,

Oihane. Economía doméstica y redes sociales en el Antiguo Régimen. Madrid: Silex, 2010.

25

Se casan en marzo de 1737. Ella era hija del coronel Marcos José de Larrazabal y de Josefa de la Quintana y Riglos, sus hermanos y cuñados forman una extensa red de militares y funcionarios que tendrán destacada actuación antes y después de la independencia rioplatense.

26

AGI-Contratación - 5485, N2, R9. Es probable que Pablo de Aoíz esté estrechamente ligado a la poderosa casa mercantil de los Ustariz de Cádiz.

27

AGI-Contratación - 5506, N2, R50, trae consigo, como era habitual, a un pariente lejano como criado. do como "meritorio" a su lado, sino que Gaspar recomienda a éste y a Narciso para ocupar un puesto como funcionarios y en esta sociedad, a nadie le parece que ello desmerezca en absoluto a los propios méritos específicos de los candidatos. Es más, esto parece ser una prueba evidente de que se trata de personas idóneas para ocupar esos cargos. No es raro que un aspirante en esta época mencione los cargos de su padre u otros antepasados como uno de los antecedentes relevantes de su hoja de vida profesional. ${ }^{16}$ En los archivos se pueden consultar decenas de solicitudes de empleos en las cuales los antecedentes familiares del solicitante son uno de los elementos claves que se supone deberán ser tomados en cuenta ${ }^{17}$; mencionemos sólo uno entre tantos: en 1800, el Administrador de la Aduana de Montevideo, requiriendo ocupar el mismo puesto en Buenos Aires, no duda en mencionar las hazañas militares de su "tío carnal", como las de su suegro y su cuñado. Obviamente, dada la relevancia de lo que llamaremos "las familias militares", este hecho era incluso más visible en la carrera de las armas. En 1783, los hermanos Miguel y Antonio Marín, subteniente y cadete del escuadrón de Dragones, presentan en la Nueva Guatemala una solicitud para pasar a Barcelona a estudiar matemáticas y poniendo como único antecedente que el padre, Antonio Marín, fue ingeniero militar y que el abuelo, Miguel Marín, llegó a Mariscal de Campo. ${ }^{18}$

También es necesario señalar que las secciones de contaduría parecen ser aquellas en donde más temprano se guardan ciertos principios de carrera y de profesionalidad - esto parece bastante normal, dada la calificación necesaria para este tipo de empleos. Pero, no debemos olvidar que el fenómeno de una genuina carrera burocrática en los funcionarios no judiciales, es relativamente tardía y la importancia de "ventas" y "beneficios"19 de los cargos siguió siendo muy relevante durante todo el siglo XVIII. ${ }^{20}$

La historia de la familia Aíoz puede ser sintomática en este sentido, pues nos muestra otra cara de la carrera de un funcionario. ${ }^{21}$ Don Pablo de Aoíz adquiere en 1740 el cargo de Alguacil Mayor de las Reales Cajas de Potosí y La Plata, entregando "un servicio pecuniario", como dicen pudorosamente las fuentes, de 14.000 pesos fuertes ${ }^{22}$, en el momento en que se inicia la segunda ola de la venta de oficios en el marco imperial acuciada la Corona por los gastos de la Guerra de Sucesión Austriaca. ${ }^{23}$ Pablo de Aoíz, de origen navarro y nacido en 1709, había llegado muy joven a Buenos Aires con los navíos de registro de Martínez de Murguía en $1717^{24}$; esposa en 1737 a doña Tomasa de Larrazabal, casamiento que lo enlaza con una familia de militares peninsulares y porteños extensa y prestigiosa. ${ }^{25}$ Pablo de Aoíz, que aparece con el titulo de "comerciante" en uno de sus viajes desde Cádiz $^{26}$ sirve en ese oficio hasta la mayor edad de su hijo Tomás, quien era el verdadero destinatario del cargo (Tomás debería tener 3 o 4 años en el momento de la compra del cargo). En 1763, Pablo vuelve otra vez de Cádiz con el titulo de corregidor de Larrecaja $^{27}$ y no casualmente ese mismo año, su hijo Tomás - que probablemente va a acompañar a su padre en el negocio del reparto de mercancías en Larrecaja - traspasa el cargo de Alguacil de las Reales Cajas de Potosí a su hermano menor Fermín, mediante un procedimiento que no resulta claro con los datos aportados por la fuente (al parecer, la decisión es paterna, probablemente, como adelanto de herencia). Pocos años más tarde, en 1770, Tomás viene también de Cádiz y trae sus alforjas el cargo 
AGI-Contratación - 5513, N44. Recordemos que el cargo de Corregidor es el equivalente en el Perú y el Alto Perú al del Alcalde Mayor en la Nueva España y su objetivo fundamental es el reparto forzoso de mercancias entre los indígenas.

29

Se trata de un cargo ya ocupado en el momento de la adquisición, se compra de este modo a futuro, AGI-Indiferente General - 525, 1 (agradezco a Francisco Andújar este dato).

30

AHN-Consejos - 20.395, expediente 2.

31

Vale la pena citar la fuente: el representante de Pablo dice, refiriéndose a Fermín "Si el deudor, sin ministerio en Buenos Ayres... se ha obstentado tan fértil de arbitrios, travesuras y expedientes para tergiversar una obligación que es limpia, que no hará en Potosi donde su representación es brillante, su poderío extendido y pública la dependencia de vecinos y jueces...", Loc. Cit., fojas 23; de hecho, cuando interviene en la causa Lamberto de Sierra, el conocido contador de las Cajas Reales, el intendente Francisco de Paula Sanz se ve obligado a reprenderlo por su parcialidad en el asunto, ver AHN-Consejos 20.395, expediente 2, fojas 48-49 vta.

32

En este estudio tomamos a la palabra

"oficina" en el sentido que le da el interesante tratado de HENRY, Ángel Antonio [1815]. El oficinista instruido o práctica de las oficinas reales... Madrid: Centro de Estudios Políticos y Constitucionales, 2000

33

AGS, SGU, legajo 6825, 5 y ARAUJO, José Joaquín de, [1803]. Op.Cit.,y Archivo General de la Nación, Buenos Aires, (en adelante AGNA), sala IX-6-1-3.

34

AGI-Buenos Aires, 27. de corregidor de Chayanta ${ }^{28}$ que su padre había adquirido para él en concepto de "futura"29, lo que indica claramente los medios económicos y la relaciones de este grupo familiar.

En 1773, mediante un arreglo extrajudicial, Fermín, que cobraba un sueldo de 3.240 pesos anuales como Alguacil, se compromete a abonar a su hermano Tomás, que seguía siendo corregidor de Chayanta, 600 pesos anuales. ${ }^{30}$ Cuando en 1780, la Corona decide suprimir el cargo de Alguacil, Fermín que ha pasado todos esos años en Potosí y conoce "a medio mundo"31, es nombrado desde enero de 1781 Oficial Contador de las Cajas Reales de Potosí y decide entonces, dado que el puesto precedente ha desaparecido, no seguir pagando los 600 pesos anuales a su hermano Tomás. Este presenta una demanda en 1781 reclamando ese pago y así nos enteramos que Fermín ahora ni siquiera habita en la gélida ciudad del altiplano, pues se halla en Buenos Aires y ha dejado en su reemplazo a un substituto - su nombre no aparece en el litigio - quien cobra una parte del sueldo de Fermín. No alarguemos esta historia (finalmente, Fermín y su cuñada, viuda de Tomás, arreglan 1786 en 300 pesos el pago anual que ella recibiria). Uno de los hijos de Tomás, Mariano de Aoíz seguirá también carrera en las oficinas ${ }^{32}$ estatales desde que entra en 1792 como meritorio a trabajar en la Contaduría de Tabacos, en julio de 1793, ya es nombrado $2^{\circ}$ Teniente visitador de Tabacos y en 1798 es nombrado Oficial $3^{\circ}$ de la Secretaria de Cámara del Virreinato, donde continuará prestando servicios al menos hasta 1803, en 1818 su nombre se incluye entre los empleados jubilados. ${ }^{33}$

Mencionemos otro caso. En las cajas reales de Potosí, fallece en diciembre de 1798 Manuel del Cerro, oficial segundo de esas cajas, donde había trabajado por 29 años; nuestro ya conocido, Fermín de Aoíz, escribe en ese momento el Intendente para recomendar el nombramiento del hijo, Felipe del Cerro, en el puesto de su padre. La foja de servicios de Felipe nos informa que, al igual que había ocurrido en el caso de los Lozano, éste había ejercido como meritorio (es decir, sin percibir salario), al lado de su padre - ya enfermo - durante casi 10 años en las cajas reales potosinas, habiendo sido nombrado en 1796, oficial tercero interino y desde inicios de 1798, oficial segundo interino. Este nombramiento como sucesor de su padre es confirmado finalmente a fines de $1798 .{ }^{34}$

Como vemos, estos ejemplos muestran que esa forma de "heredar" un puesto en la administración o de reclamarlo por méritos de sus parientes, no era nada infrecuente. Lo que nos importa señalar aquí, amén del fenómeno de las redes familiares que hemos analizado en los tres casos, es este estilo de arreglos privados (recuérdese que también Lozano ofrecía dividir el sueldo con su hijo Narciso antes de su jubilación, para que éste después de su muerte lo reemplazara) en los que el puesto - con más razón en el ejemplo de los Aoíz, pues el primer cargo había sido efectivamente comprado - puede pasar de mano en mano como si fuera un bien cualquiera y sobre él se puede hacer estos arreglos tan peculiares. Todo ello dibuja de forma muy precisa al tipo de carrera burocrática que realizan efectivamente estos funcionarios y señalemos que estamos ya en las puertas de la revolución de independencia cuando se considera que el funcionamiento de la burocracia imperial hispana se acerca más al modelo "racional". Y en efecto, podemos constatar varios hechos que apuntan en este sentido, como la obligación de presentar las fojas de servicios y las calificaciones obtenidas durante el transcurso de los empleos ejercidos o el hecho de 
35

LÓPEZ BEJARANO, Pilar. "Organización e incertidumbre. Dinámica administrativa de la secretaría de hacienda de la nueva granada (1806-1851)", 2011, mss.

36

RODRÍGUEZ SOLANO, Pablo. "Metamorfosis estatal: evolución de la organización institucional-burocrática en Costa Rica entre 1786-1842", 2011, mss.

37

LLOPIS AGELÁN, Enrique. Expansión, reformismo y obstáculos al crecimiento (1715-1789). In: COMíN, Francisco, HERNÁNDEZ, Mauro y LLOPIS, Enrique. Historia económica de España, siglos X-XX. Barcelona: Crítica, 2002; PRADOS DE LA ESCOSURA, Leandro. De imperio a nación: crecimiento y atraso económico en España, 1780-1930. Madrid: Alianza Editorial, 1988; O'BRIEN, Patrick. European Economic Development: The Contribution of the Periphery. The Economic History Review, new series, 35 (1), 1982. Una visión contraria: FONTANA, Josep. La quiebra de la monarquía absoluta. Barcelona: Crítica. 2000; MARICHAL, Carlos y SOUTO MANTECON, Matilde. Silver and Situados: New Spain and the Financing of the Spanish Empire in the Caribbean in the Eighteenth Century. Hispanic American Historical Review, 74 (4), 1994; MARICHAL, Carlos. La bancarrota del virreinato, Nueva España y las finanzas del imperio español, 1780-1810, México: El Colegio de México/FCE, 1999; GARAVAGLIA, Juan Carlos. Economía colonial y economía-mundo en un siglo de expansión. In: GARAVAGLIA, Juan Carlos y MARCHENA FERNÁNDEZ, Juan. América Latina. De los orígenes a la Independencia. Volumen II - La sociedad colonial ibérica en el siglo XVIII. Barcelona: Crítica, 2005. En realidad, después del libro de POMERANZ, Kenneth. The Great Transformation: China, Europe, and the Making of the Modern World Economy. Princeton: University Press, 2000, es difícil continuar negando el rol de los metales preciosos americanos en la economíamundo desde el XVI y España jugó un papel de primer plano en ese aspecto.

38

DREYFUS, Françoise. L'invention de la

bureaucratie. Servir l'état en France, en GrandeBretagne et aux Etats-Unis (XVIIIe-XIXe siècle). Paris : La Découverte, 2000. respetar la antigüedad en el otorgamiento de nuevos cargos. Como vemos, la administración del Imperio se hallaba en las puertas de la revolución de independencia en un momento realmente transicional de su larga historia, entre la lógica "patrimonial" y una tímida "racionalización" según afirma Francisco Andújar.

\section{La estructura de las oficinas de gobierno}

Una de las cosas que rápidamente llaman la atención al estudiar la manera en que se estructuran las oficinas de gobierno a fines del periodo colonial, es la decidida orientación hacia la maximización de la recaudación fiscal, como afirma Pilar López Bejarano "El orden y el funcionamiento del Ministerio de Real Hacienda se confunde con el gobierno mismo. En la medida en la que la principal labor del gobierno colonial, en este período, es la de una eficiente recaudación fiscal... toda su administración se estructura alrededor de los agentes encargados de esta labor"35. Ese trabajo sobre la Nueva Granada y el estudio de Pablo Rodríguez Solano referido a la superintendencia de Guatemala ${ }^{36}$, muestran en forma harto evidente este esquema que vemos repetirse hasta el cansancio en todos los casos americanos estudiados. Esto no debería extrañarnos, por supuesto, dado que se trata de una relación colonial que se funda en claros objetivos de obtención de beneficios para la Corona y si bien algunos especialistas niegan hoy la relevancia de la relación colonial para la economía española de la época, creemos que la discusión sigue sin estar saldada. ${ }^{37}$ Como veremos seguidamente, la fiscalidad siguió estando en el corazón de las nuevas experiencias estatales, pero fue indispensable operar un cambio radical en la mentalidad de los funcionarios de hacienda, hecho que no fue ni fácil, ni sencillo de lograr.

\section{La ruptura revolucionaria}

Los cambios en la organización de la burocracia

A decir de Alexis de Tocqueville ${ }^{38}$, la continuidad estatal con el pasado, (hecho que parecia ser desmentido en su época por las revoluciones políticas sucedidas a partir de 1789), surgiría de estabilidad de las estructuras administrativas que persistirian pese a los profundos cambios políticos ocurridos después de la gran Revolución de 1789. La administración estatal sería entonces, el nexo entre el "pasado" del Antiguo Régimen y el "presente" revolucionario, constituiría asi el gran hilo de continuidad entre las dos épocas. Obviamente de esta observación de Tocqueville, resultan las primeras preguntas que uno tendría que hacerse en relación a las revoluciones de independencia en lbero América: ¿Alteraron éstas las estructuras administrativas? ¿Y si fue así, cómo se reconstruyó, en el día a día revolucionario, el funcionamiento de la burocracia? Por otra parte, ¿qué pasó con las carreras de los funcionarios al llegar la revolución, hay o no continuidad entre un periodo y el otro? Es evidente que la respuesta a estas preguntas solo puede venir de los análisis pormenorizados de cada uno de los casos que estamos estudiando, no puede haber una respuesta a priori y dadas las distintas situaciones, no sólo en cuanto al momento de la ruptura (1810, $1817,1819,1821$, etc.), sino también en relación a la forma, violenta o relativamente pacifica de esa ruptura, los cuadros pueden ser bastante diversos. En este sentido, Chile o Buenos Aires presentan el polo opuesto de Guatemala o Costa Rica. 
39

Esta expresión posiblemente ha sido tomada del francés, pues algunos autores del XVIII, como Condorcet, se refieren a la ciudadanía como el "droit de cité" (cité en el sentido de polis obviamente).

40

Registro Oficial de la República Argentina (RORA), Tomo I, p.91-92, 3/12/1810.

41

"El Gobierno Superior Provisional de las Provincias Unidas del Río de la Plata à nombre del Señor Don Fernando Séptimo. Por cuanto D... después de haber dado las pruebas más positivas de su adhesión a la causa santa de la libertad del pueblo americano... ha venido en declararle, como le declara, ciudadano americano del Estado...", RORA, Tomo I, p.172, disposición del mes de julio de 1812, bastardillas nuestras; algunas cartas de ciudadanía, AGNA, X-23-4-8 y solicitudes de ciudadanía, AGNA, X-3-8-10.

42

BARROS ARANA, Diego [1884]. Historia jeneral de Chile. Santiago de Chile: Editorial Universitaria, 2006.

43

Ver RORA, Tomo I, passim.

44

RODRígueZ SOLANO, Pablo. Op. Cit.

45

SARAZÚA, Juan Carlos. "Formación y expansión de la burocracia en Centroamérica: la Federación y el Estado de Guatemala (1823-1840)", 2011, mss.
Un primer elemento relevante es la cuestión de la lealtad al nuevo orden en construcción. Tanto en el Río de la Plata, como en la primera experiencia de la junta instalada en Chile, se exige a los antiguos funcionarios una estricta fidelidad a la causa "americana". En Buenos Aires se comienza por limitar el acceso a todo "empleo público à persona que no haya nacida en estas Provincias", exceptuando, lógicamente, a los "empleados europeos actualmente existentes" siempre que manifiesten su "buena conducta, amor al país y adhesión al Gobierno". En esta disposición se habla por vez primera de "derechos de ciudad"39 [sic] y se agrega que "las naciones todas justifican este regla... pues en ninguna se divide el gobierno con hombres estraños"40. En poco tiempo, se establecen allí las "cartas de naturaleza" y en 1812, el primer triunvirato confección un formulario ad $h_{o c^{41}}$. En Santiago de Chile, según nos cuenta Barros Arana en su Historia eneral... una disposición de septiembre de 1811 dice "Despues que este gobierno ha publicado las sagradas bases que fijan su sistema, sería el crímen mas alto la indiferencia en cualquier miembro del estado; pero con mayor gravedad en los que tienen el honor de merecer su inmediata confianza por los empleos con que los ha distinguido la patria. No cree, en consecuencia, este poder (la junta) que abrigue ideas tan bajas, clase ni aun individuo alguno de las privilegiadas; sin embargo, ha resuelto, en desempeño de su alto ministerio, que en adelante llene la segunda casilla de las notas en toda hoja de servicios la cualidad de patriotismo, sobre el concepto de que solo se clasificarán por una opinión comprobada de hecho, que la indiferencia será un crímen acreedor a la separación del servicio"42.

Como sabemos, en ambos casos, Chile y el Río de la Plata, cuando la guerra dio comienzo en forma abierta, la confiscación de los bienes y en algunos casos la prisión de los "españoles europeos" no afectos al régimen, fue una realidad indudable, pero no tenemos muchas fuentes para captar hasta que punto muchos de los peninsulares que abandonaron su puesto 0 se jubilaron, lo hicieron de buena gana. En Buenos Aires el Registro Oficial constata a lo largo de sus páginas, la reiteración de disposiciones que dejan fuera de la administración a los funcionarios "sospechosos" y en algunos casos, ni siquiera se les permite jubilarse (en otros, se los jubila, pero sin estipendio.... $)^{43}$. En Chile, la disposición ya citada de 1811 dice "que serán mirados i tratados como reos de lesa patria los que, desgraciadamente, observaren otra conducta" que la de la fidelidad al nuevo orden. Pero, hay que señalar que en otros casos, por ejemplo, en Centro América, la transición iniciada en 1821 al nuevo orden fue relativamente tranquila, asegurando una cierta estabilidad de la burocracia y no parece haber habido un despido masivo de funcionarios, según lo podemos comprobar a través de los trabajos sobre Costa Rica ${ }^{44}$, como sobre Guatemala y la república federal centroamericana. ${ }^{45}$

Pero, hay aquí otra cuestión fundamental. Cuando se está rompiendo el vínculo con la Madre Patria, es indispensable que esta burocracia en reorganización tome consciencia de estar ahora a la cabeza de un nuevo experimento político (la construcción de un Estado soberano), por lo tanto, debe renunciar a ser pasivamente una pequeña rama del gran árbol de la burocracia imperial y necesita aprender a programar hacia el futuro. Antes "solo" obedecia, ahora debe formarse para innovar. Hay aquí un cambio que podriamos llamar estructural en la concepción de la administración de la cosa pública. Esto no es poco, pues presupone una mudanza en la mentalidad que debe hacer tomado un tiempo en instalarse, especialmente 
RORA, Tomo I, p.27, "Reglamento para el ejercicio de la autoridad de la Junta del 28 de Mayo de 1810", artículo III.

47

AGNA, X-3-1-11, "Reglamento provisional de las Secretarias del Estado en sus respectivos Ministerios de Gobierno, grra. y hacienda".

48

LÓPEZ TAVERNE, Elvira. Op. Cit.

49

ETCHECHURY BARRERA, Mario Israel. “¿Recaudar sin burocracia? Gobiernos republicanos y Antiguo Régimen fiscal en el Estado Oriental. Una aproximación a través del arriendo de impuestos. 1828-1852", 2011, mss.

50

RODRÍGUEZ SOLANO, Pablo. Op. Cit. 51

GARAVAGLIA, Juan Carlo. "Algunos aspectos preliminares acerca de la 'transición fiscal'...", Op. Cit.

52

La bibliografía europea sobre el tema es inmensa; una visión general comparativa en TILLY, Charles. Coercion, Capital and European States, AD990-1990. Cambridge: Basic Blackwell Massachusetss., 1990 y MANN, Michael. The Sources of Social Power. Vol.I, - A History of Power from de the begining to A.D. 1760. Cambridge University Press, 1986. Ver también los trabajos incluídos en GENET, Jean-Philip y LE MENÉ, Michel. Genèse de l'État moderne. Prélèvement et redistribution. Actes du Colloque de Fontevraud. Paris: Centre National de la Recherche Scientifique, 1987. Para el caso inglés especificamente: BREWER, John. The Sinews of Power. War, Money and the English State, 1688-1783. New York: Alfred A. Knopf, 1989, y O'BRIEN, Patrick K. and HUNT. Philip A.. England 1485-1815. In: BONNEY, Richard. The rise of the fiscal state in Europe, c.1200-1815. New York, Oxford University Press, 1999. Para Francia, LE GOFF, Jacques. Genèse de la France. (milieu IXe- fin XIIle siècle): vers un État monarchique français. In: REVEL, Jacques y BURGUIĖRE, André Histoire de la France, L'État et les pouvoirs. Paris : Seuil, 1989 y COLLINS, James B. State Building in Early-Modern Europe: the Case of France. Modern Asian Studies, 31, 3, 1997. El caso de España ha sido tratado por varios autores, entre ellos, GLETE, Jan. War and the State in Early Modern Europe: Spain, the Dutch Republic and Sweden as fiscal military states, 1500-1660. London and New York, Routledge, 2002, TORRES SÁNCHEZ, Rafael (ed.). War, State and Development. Fiscal-Military States in the Eighteenth Century. Universidad de Navarra, Pamplona, Eunsa, 2009 y JURADO SÁNCHEZ, José. Military expediture, spending capacity and budget constraint in eighteenth-century Spain and Britain. Revista de Historia Económica - Journal of Iberian and Latin American Economic History, año n.27, n.1, 2009, p.141-174. porque en los primeros años la cuasi única preocupación era... pagar a las tropas. Todo ello presupone también una alteración bastante a fondo de la organización de las oficinas del estado. Es evidente que esta reorganización no se podrá realizar de un día para el otro, pero, en dos casos tempranos, los de Buenos Aires y Chile, ya desde el inicio mismo de la revolución, se crean los Departamentos (también llamados a veces Ministerios o Secretarias) y esto significa un cambio radical en la estructura misma de la burocracia estatal.

En Buenos Aires, tres días después del coup d'état del 25 de mayo de 1810, es decir, el 28 de mayo, se comienza a establecer un nuevo organigrama de gobierno -sin tocar, por ahora, el heredado del periodo precedente - instituyéndose dos Departamentos, el de Gobierno y Guerra y el de Hacienda. ${ }^{46}$ Un documento sin fechar del Archivo de Buenos Aires probablemente es de esos mismos días ${ }^{47}$ - establece un Reglamento, acompañado de una corta lista de funcionarios para cada Departamento. En Chile se crean el 19 de mayo de 1811 "cuatro secciones al interior del gobierno, equivalentes a las futuras secretarias o ministerios: estado, hacienda, guerra y policia".48 En el caso de la provincia Oriental del Uruguay durante el periodo artiguista, el Ministerio de Hacienda es ya una realidad en 1815, pero, ello no obstaba para que las antiguas prácticas coloniales de recaudación en gran medida siguieran vigentes. ${ }^{49}$ Nuevamente, dadas las diferencias de fecha en los movimientos independentistas, en la Nueva Granada se inicia en 1819 (con el nombre de Superintendencia general de Hacienda) y en la experiencia centroamericana esto ocurre desde $1825 .^{50}$

Lo que es importante subrayar aqui en cuanto a los cambios ocasionados por la ruptura independentista acerca de la burocracia, es esta realidad de una nueva conformación de las oficinas estatales. $Y$ esta renovada conformación está centrada en dos objetivos fundamentales y de acuerdo a lo que sabemos por datos que hemos estudiado sobre la evolución de la fiscalidad ${ }^{51}$, ellos constituyen los pilares de la construcción estatal durante todo este periodo: el ejercicio de la violencia - hacia afuera y hacia adentro - y la búsqueda de los medios adecuados para financiarlo.

\section{Los números de la burocracia}

El segundo aspecto que es de gran relevancia se refiere a tema del crecimiento o no de la burocracia en función del proceso de construcción estatal. Como es sabido, los estudios clásicos europeos sobre la cuestión muestran una relación bastante estrecha entre el crecimiento de la burocracia y las necesidades de financiación de las guerras en el proceso de construcción de los estados europeos de la modernidad ${ }^{52}$. Veremos seguidamente, la situación en América lbérica es bastante disímil según los casos. Comencemos por Chile, el cuadro 2 nos muestra los datos según el estudio de Elvira López Taverne.

Cuadro 2: Chile, funcionarios por ministerio 1845-1860

\begin{tabular}{|l|l|l|l|l|}
\hline & 1845 & 1850 & 1855 & 1860 \\
\hline Interior y RR.EE & 129 & 130 & 166 & 257 \\
\hline Justicia e Instrucción pública & 176 & 266 & 429 & 820 \\
\hline Hacienda & 440 & 406 & 467 & 590 \\
\hline Total & 745 & 802 & 1.062 & 1.667 \\
\hline
\end{tabular}

Fuente: LÓPEZ TAVERNE, Elvira. "La configuración de un cuerpo burocrático en el marco del proceso de construcción estatal. Chile 1810-1860", 2011, mss. 
"El crecimiento de este departamento se relaciona con dos procesos que se viven al mismo tiempo. Por una parte la creación de nuevas instituciones de educación superior, escuelas especiales, como las de sordomudos, la Escuela Normal, la Escuela de Artes i Oficios, y la Academia de Pintura; y por otra parte el desarrollo de la red de escuelas primarias, fenómeno que explica el importante aumento que observa la dotación de esta sección. En 1845 se contabilizan 83 escuelas, 120 en 1850, y 427 en 1860.", LÓPEZ TAVERNE, Elvira. Op. Cit.

54

El Estado de Buenos Aires existió entre 1852 y 1861, cuando la provincia, desconforme con el papel del general Urquiza, se separó de la Confederación Argentina.

55

SOCOLOW, Susan Migden. The Burocrats of Buenos Aires, 1769-1810:Amor al Real Servicio. Durham: Duke University Press, 1987 y ARAUJO, José Joaquín de [1803]. Op. Cit.
SARAZÚA, Juan Carlos. Op. Cit
Hay aquí un aumento indudable en el número de funcionarios, pero, no es general ni toca a todos los departamentos en el mismo momento. El Departamento de Hacienda decrece hasta 1850 y se puede decir que sube realmente a fines del periodo, en cambio, el Departamento de Justicia e Instrucción Pública es el único que tiene un incremento exponencial de sus empleados, ello se relaciona en este caso con una cuestión: el incremento del gasto en la educación, tanto primaria, como especializada. ${ }^{53}$ Esto es una de las formas de "despliegue" de las funciones estatales que, en el caso chileno, se dan muy tempranamente.

Para el caso de la provincia y el Estado de Buenos Aires ${ }^{54}$, tenemos los datos del cuadro siguiente, ordenados de distinta manera, pero que nos muestran en forma muy clara, no sólo el crecimiento de la burocracia civil a fines del periodo, sino también, la relación entre los empleados en las oficinas estatales y el resto del personal que cobra sueldos sin pertenecer a la burocracia civil (en este caso, se trata de serenos nocturnos, guardias del resguardo de las aduanas y policías urbanos). Señalemos, antes de analizar el cuadro, que hemos partido de una cifra de alrededor de 147 a 151 empleados a fines de la época colonial. ${ }^{55}$

Cuadro 3: Provincia y Estado de Buenos Aires: personal de control/represión y burocracia civil

\begin{tabular}{|c|c|c|c|c|c|}
\hline & \multicolumn{2}{|c|}{ Control y Represión } & \multicolumn{2}{c|}{ Burocracia Civil } & Totales generales \\
\hline 1823 & 122 & $3.8 \%$ & 297 & $8.5 \%$ & 3.489 \\
\hline 1841 & 1.300 & $13.6 \%$ & 296 & $3.1 \%$ & 9.518 \\
\hline 1861 & 1.014 & $11.6 \%$ & 1.143 & $13 \%$ & 8.741 \\
\hline
\end{tabular}

Fuente: AGN, Buenos Aires, X-12-3-15

La diferencia entre el total general y el resto del personal del estado se relaciona, como era de imaginar, con el peso de "las fuerzas de guerra", es decir, el personal del ejército y la marina. Las conclusiones son obvias, en 1861, pese al sostenido crecimiento de los empleados civiles, éstos son sólo el 13\% del total de los individuos que cobran un estipendio estatal y este hecho nos muestra, una vez más, cuál es el papel que juega el ejercicio de la violencia interior y exterior. En cuanto a los empleados en las oficinas del Departamento de Hacienda y de economía en general (éstos son los empleados de las cámaras legislativas que fiscalizan la evolución del crédito público), tenemos cifras que presentan una evolución bastante paralela a la de Chile, con 137 funcionarios en 1823, 121 en el año 1841, para recién dar un salto a 347 en 1861.

En el caso del Estado de Guatemala, en el marco de la Confederación Centroamericana, nos hallamos frente a un crecimiento constante de la burocracia civil en este breve periodo que precede a la ruptura de la unión confederal en $1838^{56}$.

Cuadro 4: Estado de Guatemala, empleados 1826-1837

\begin{tabular}{|c|c|c|c|c|c|}
\hline & \multicolumn{2}{|c|}{ Control, represión y ejército } & \multicolumn{2}{|c|}{ Burocracia civil } & Totales generales \\
\hline 1830 & 572 & $87.5 \%$ & 82 & $12.5 \%$ & 654 \\
\hline 1832 & 913 & $86.4 \%$ & 143 & $13.5 \%$ & 1.056 \\
\hline 1837 & 1.577 & $89.8 \%$ & 180 & $10.2 \%$ & 1.757 \\
\hline
\end{tabular}

Fuente: SARAZÚA, Juan Carlos. "Formación y expansión de la burocracia en Centroamérica: la Federación y el Estado de Guatemala (1823-1840)", 2011, mss. 
VELASCO HERRERA, Viviana. "Administrar el poder: funcionarios y oficinas en el proceso de construcción del Estado ecuatoriano, 18301845", 2011, mss.
El caso ecuatoriano ha sido estudiado por Viviana Velasco Herrera ${ }^{57}$. El cuadro 5 nos muestra los datos principales en lo que hace a los números de la burocracia a mediados del XIX.

Cuadro 5: empleados por Departamento, Ecuador, 1837-1843

\begin{tabular}{|l|c|c|c|c|}
\hline Ramo & 1837 & 1839 & 1841 & 1843 \\
\hline Interior y gobierno & 77 & 79 & 83 & 68 \\
\hline Justicia & 45 & 26 & 30 & 31 \\
\hline Hacienda & 284 & 323 & 293 & 338 \\
\hline Subtotal civiles & 406 & 428 & 406 & 437 \\
\hline Fuerzas armadas & 1.468 & 1.564 & 2.965 & 2.399 \\
\hline Total & 1.874 & 1.992 & 3.371 & 2.836 \\
\hline
\end{tabular}

Fuente: VELASCO HERRERA, Viviana. "Administrar el poder: funcionarios y oficinas en el proceso de construcción del Estado ecuatoriano, 1830-1845", 2011, mss.

En estos años es visible que el personal del Departamento de Hacienda dominaba claramente en el cuadro general de la administración, lo que no puede sorprendernos evidentemente. Hay pequeñas variaciones en los respectivos años, pero éstas no inciden en este panorama. También es interesante comprobar que - sin tener cifras acerca de policías, guardianes urbanos y gendarmes (que dependen de los municipios) - la relación entre personal civil y miembros de las fuerza de guerra, es similar a la que presentan los restantes casos latinoamericanos que estamos estudiando.

Y llegamos así a la excepción en este panorama general de crecimiento para fines del periodo: la Nueva Granada. Las cifras que aporta el estudio de Pilar López Bejarano, muestran una evolución completamente diferente, en la cual, el peso de la burocracia del estado parece disminuir a medida que avanza el siglo XIX y ello sigue ese mismo ritmo decreciente al menos hasta los años cincuenta del XIX, si nos guiamos por el número de empleados de Hacienda. Este hecho es perfectamente compatible por lo que sabemos acerca de la fiscalidad colombiana del periodo. Como se puede observar, los empleados del departamento de hacienda son cada vez menos numerosos; recordemos que esto tiene que ver con el proceso de descentralización administrativa que llevará a la confederación Granadina en 1858 y a los Estados Unidos de Colombia en 1862 y también, esta disminución está relacionada con la eliminación del monopolio del tabaco durante esos años.

Cuadro 6: Nueva Granada, empleados con sueldo de la Secretaría de Hacienda

\begin{tabular}{|l|c|c|c|}
\hline & 1806 & 1842 & 1851 \\
\hline Personal de oficina & 714 & 452 & 278 \\
\hline Personal de resguardo & 235 & 472 & 219 \\
\hline Total & 949 & 924 & 497 \\
\hline
\end{tabular}

Fuente: LÓPEZ TAVERNE, Elvira. "La configuración de un cuerpo burocrático en el marco del proceso de construcción estatal. Chile 1810-1860", 2011, mss.

Hagamos un alto y veamos cuál es la relación entre empleados civiles y militares en los casos en que tenemos esa información. En 1850 hay en Chile 2.634 miembros de las fuerzas armadas que cobran un salario, si lo comparamos con los 802 empleados civiles, vemos que un $76.6 \%$ del personal que cobra un estipendio estatal es militar. Pero, pero... no olvide- 
58

ETCHECHURY BARRERA, Mario Israel. Op. Cit.

59

RODRÍGUEZ SOLANO, Pablo. Op. Cit.

60

ETCHECHURY BARRERA, Mario Israel. Op. Cit.

61

FRADKIN, Raúl Osvaldo. Las formas de hacer la guerra en el litoral rioplatense. In: BANDIERI, Susana. La historia económica y los procesos de independencia en la América hispana. Buenos Aires: Prometeo, 2009. mos que las fuerzas policiales dependen de las municipalidades. En 1842 el cuerpo de policía de la ciudad de Santiago asciende a 255 empleados (vigilantes y serenos) y en 1845 , el recién estructurado cuerpo policial de Valparaiso, tiene 206 empleados. Es decir, si suponemos unos 500 empleados de policia y serenos para todas las municipalidades (número quizás bajo, pero, eso no importa ahora), veremos que alrededor del $80 \%$ de quienes reciben un sueldo, sea estatal, como municipal, está comprendido en las funciones militares y de represión. Para Guatemala y Buenos Aires las cifras son aún más altas: el 90\% del personal que cobra un salario en Guatemala en 1837 y el 97\% en la provincia de Buenos Aires en 1841, pertenece a las fuerzas armadas o a los distintos cuerpos de seguridad interior. Ocurre algo similar en el Estado Oriental del Uruguay en 1838-1839, el 93\% de las 2.831 personas que cobran un salario estatal, son militares y policias ${ }^{58}$. En Ecuador, como podemos comprobar gracias al cuadro 5 precedente, la relación entre empleados civiles y militares, muestra - promediando los datos de los cuatro años - que un 83\% de los que reciben un salario estatal son miembros de las fuerzas de guerra. También en Costa Rica en la época de Braulio Carrillo a fines de los años treinta, nos hallamos con proporciones semejantes, pues tenemos 969 miembros del ejército y la marina en 1848, frente a una estimación de alrededor de 90 empleados civiles del estado (de esos, unos 50 pertenecen al Departamento de Hacienda) y hay que subrayar aquí que el crecimiento de la burocracia ha sido espectacular, pese a la humildad de las cifras, pues hemos partido de un muy reducido puñado de funcionarios en el momento de creación de Costa Rica como estado independiente ${ }^{59}$. Es decir, en todos los casos en los que los datos son accesibles, vemos que a mediados del siglo XIX, el personal del estado se compone de una muy delgada burocracia y de una "engordada" cohorte de soldados, policias, serenos [guardianes nocturnos], guardias rurales, gendarmes, etc.

En el marco de este vasto cuadro que estamos desplegando, hay casos y temas más específicos que resultan interesantes abordar. El primero de ellos se refiere a la peculiar situación del Estado Oriental del Uruguay. ${ }^{60}$ Esta sólo puede ser entendida si recordamos que el estado oriental se construye en medio de una situación de guerra que durará, casi sin interrupciones, durante cuarenta años. ${ }^{61}$ La Banda Oriental dependia de Buenos Aires hasta la ruptura de 1810, pero, por una parte, la reacción de los "españoles europeos" contra la junta de Buenos Aires, más el detalle de ser Montevideo una plaza fuerte y un Apostadero Naval, convierten a la ciudad oriental en un espacio privilegiado de oposición realista a la junta porteña. Además, el caudillo de la campaña oriental, José Gervasio de Artigas, chocará repetidamente con los dirigentes porteños que, resistiendo ferozmente cualquier intento de experiencia "federal", se enfrentarán con él. Si le sumamos a ello, el hecho de la invasión portuguesa en 1816 y el posterior levantamiento de la campaña contra los invasores en 1825, lo que da pié a una guerra entre el Imperio del Brasil y la Confederación Argentina, apoyando ésta a los orientales levantados contra los ahora brasileños, el panorama de los primeros años de la experiencia independentista en la Banda Oriental resultaron francamente movidos y ello explica, entre otras cosas, el desorden de la administración en medio de estos episodios bélicos y a la vez, la persistencia de no pocas de las prácticas coloniales de recaudación, como de muchos de los funcionarios que las encarnaban. Al mismo tiempo se puede señalar la "concurrencia" fiscal de poderes antagónicos operando 
62

DE LOS RÍOS, Evangelina. "Estudio de una administración provincial a través del examen del departamento de Hacienda (Santa Fe, segunda mitad del siglo XIX)", 2011, mss.

63

Menos la aduana de Buenos Ares, de lejos la más importante, dado que la provincia porteña ha formado el Estado de Buenos Aires (1853-1861). Los salarios y otros gastos de las fuerzas de guerra provinciales han sido trasladados ahora a la Confederación, como resultado de los acuerdos legales mencionados de 1852 y 1853.

64

ROMANO, Silvia. Economía, sociedad y poder en Córdoba, primera mitad del siglo XIX. Córdoba: Ferreyra Editor, 2002; SCHALLER, Enrique César. "Las finanzas públicas de Corrientes durante la organización Constitucional (1851-1861)". Resistencia: Universidad Nacional del Nordeste, 1996; CORIA, Luis Alberto y VARO, Roberto. Federalismo y República reales en tres décadas de presupuestos provinciales (Mendoza, 18531883). Anuario del Centro de Estudios Históricos Carlos S.A. Segreti, n.01, 1980; HERRERA, Claudia. Fiscalidad y poder: las relaciones entre el estado tucumano y el Estado central en la formación del sistema político nacional, 1852-1869. En: BRAGONI, Beatriz y MÍGUEZ, Eduardo (eds.). Un nuevo orden político. Provincias y estado nacional, 1852-1880. Dédalo: Buenos Aires, 2009. sobre un mismo espacio: entre 1825 y 1828, mientras subsistía el gobierno brasileño en Montevideo y varios puntos del territorio, las autoridades orientales iban creando instituciones administrativas y fiscales propias. $\mathrm{Ni}$ que decir entre 1843 y 1851, durante el periodo de la Guerra Grande, con el Gobierno del Cerrito - el de los sitiadores de la ciudad - por un lado y el de La Defensa por el otro.

Cuando en 1828, nace el Estado de Montevideo, luego denominado Estado Oriental del Uruguay, como resultado de los acuerdos de paz entre el Imperio del Brasil y la Confederación (santificados por la presencia británica que no tenía el menor interés en que un mismo estado controlara las dos orillas del Plata), estas prácticas "antiguas" y estos funcionarios continuaron su presencia en Montevideo y su campaña. Los hechos bélicos posteriores, sobre todo, los relacionados con la larguísima Guerra Grande (1838-1852) no hicieron más que acentuar muchos de estos aspectos y el estudio de Mario Etchechury nos muestra un cuadro en el que dominan el arrendamiento de los distintos impuestos, la venta de derechos de percepción de otros, el pago a los empleados del estado en papeles (éstos serían después descontados por un restringido grupo de mercaderes/financistas y de estancieros/comerciantes). Ellos, obviamente, son los mismos que han arrendado los impuestos y que, con toda lógica, terminan teniendo en sus manos la llave de la fiscalidad. En realidad, no es muy distinto al papel que estos mismos sectores 0 grupos similares -llamados agiotistas en el Anáhuac - jugaron en México, Bogotá, Quito o Buenos Aires. La diferencia es que aquí la situación llega realmente al paroxismo y la experiencia estatal resulta enflaquecida y condenada a un papel de casi total subordinación a estos grupos de financistas. Habrá que esperar el fin de la Guerra Grande, la derrota de Rosas en Buenos Aires (1852) y la apertura de una nueva etapa en el Estado Oriental bajo la mirada vigilante del Brasil, para que las cosas comiencen a tomar otro derrotero. Es decir, hasta ese momento, la delgada burocracia de estado en el Uruguay, se ocupaba de administrar los fondos recaudados por otra "burocracia", privada ésta, que respondía a los grupos mercantiles que habían arrendado o directamente, comprado la percepción impositiva. Es más, ambas burocracias debian convivir y asistirse mutuamente, amparadas por la fuerza armada controlada desde Montevideo, que en varios periodos funcionó prácticamente como una ciudad-estado.

Otra situación especial es la de la provincia de Santa Fe en el periodo que va desde la Confederación a la República Argentina, es decir, los años 1855-1876. Los datos del trabajo de Evangelina de los Ríos ${ }^{62}$ nos permiten ver algo que se repite hasta el cansancio en los presupuestos provinciales rioplatenses: hasta los años 1853/1854, las entradas fundamentales de los presupuestos provinciales surgen de las aduanas - exteriores e interiores y el gasto más relevante es el de las fuerzas de guerra. Desde el momento en que las provincias pierden el control de las aduanas, como resultado de los Acuerdos de San Nicolás de 1852 y la posterior constitución de 1853, estatuto legal que funda la Confederación Argentina (las aduanas interiores desaparecen y las exteriores pasarán todas, de manera progresiva, a depender del estado confederal, pero también abandonan el mantenimiento del ejército $\left.{ }^{63}\right)$, las provincias deben ingeniárselas para realizar las más variadas piruetas financieras para poder sostenerse, viviendo casi siempre en perpetuo déficit y ahora el gasto más relevante suele ser el de la policía urbana y rural y en segundo lugar, la organización judicial (hay ahora ejemplos de otras provincias ${ }^{64}$ ). 
Es decir, volvemos a ver, pero en escala reducida, un cuadro similar al de los estados nacionales, con las fuerzas de represión y de control social como el elemento fundamental de la construcción del estado. De todos modos, ya a fines del periodo estudiado por Evangelina de los Ríos es perceptible también la creciente importancia de los gastos en educación.

Cuadro 7: Provincia de Santa Fe, funcionarios provinciales, 1856-1874

\begin{tabular}{|l|c|c|c|c|c|c|}
\hline & \multicolumn{2}{|c|}{$1856 / 57$} & \multicolumn{2}{c|}{1865} & \multicolumn{2}{c|}{1874} \\
\hline & Número & $\%$ & Número & $\%$ & número & $\%$ \\
\hline Gobierno & 18 & 6.2 & 16 & 4.6 & 46 & 6.3 \\
\hline Policia & 139 & 48.3 & 184 & 53 & 520 & 71.1 \\
\hline Justicia & 18 & 6.2 & 39 & 11.2 & 53 & 7.2 \\
\hline Hacienda & 10 & 3.5 & 15 & 4.3 & 21 & 2.8 \\
\hline Educación & 25 & 8.7 & 35 & 10 & 45 & 6.2 \\
\hline Varios* & 78 & 27 & 58 & 16.7 & 46 & 6.3 \\
\hline totales & 288 & 100 & 347 & 100 & 731 & 100 \\
\hline
\end{tabular}

* En este rubro se incluyen sobre todo, los miembros de la banda de música que tuvo una importancia bastante relevante hasta 1863.

Fuente: DE LOS RÍOS, Evangelina. "Estudio de una administración provincial a través del examen del departamento de Hacienda (Santa Fe, segunda mitad del siglo XIX)", 2011, mss.

Como consecuencia de ello, el rol de la burocracia de hacienda es bastante reducido si se piensa, por ejemplo, que la provincia mantendrá hasta los años 1870/1876 un corto número de funcionarios en esa área, mientras crece en forma constante la cantidad de policias y de jueces. Como se puede apreciar a través de los datos del cuadro 6, éstos pasan de ser el $54.5 \%$ del total de los funcionarios del estado provincial en 1856/57 (en esos años los presupuestos se confeccionaban por periodos económicos y no por años calendario) al $78.3 \%$ en 1874, mientras que los empleados del Departamento de Hacienda, oscilan entre el 3.5\%, en el primer año al $2.8 \%$ a fines del periodo. Creemos que el cuadro casi habla por sí mismo.

En una palabra, sea que hagamos referencia a los ejemplos de estados nacionales que hemos analizado, como a nivel de este estado provincial argentino, la situación es muy semejante en cuanto al papel de las fuerzas de guerra, como las de represión y control, en el marco del conjunto de la burocracia.

\section{Algunas cuestiones finales}

Redes familiares y burocracia después de la ruptura

Esta es una sociedad heredera directa del Antiguo Régimen del mundo ibérico y en la cual las redes familiares eran una parte sustancial del entramado social, como vemos con en caso de Buenos Aires. ${ }^{65}$ Como también lo muestran otros autores, no era de extrañar que éstas siguieran jugado un papel relevante también entre los funcionarios estatales del periodo posterior. ${ }^{66}$ Obviamente, esta cuestión debería ser tratada en consonancia con otro aspecto fundamental que ya hemos evocado al comenzar este trabajo: ¿Hay ruptura o continuidad en las carreras de los funcionarios después de la independencia? Pero, vamos a dejar esta cuestión para más adelante.

En un trabajo que hemos realizado sobre el tema de las redes familiares y la burocracia en el Río de la Plata, presentamos varios ejemplos de familias de funcionarios que atravesaron sin demasiados problemas las dos 
GARAVAGLIA, Juan Carlos. La burocracia en el Río de la Plata..., Op. Cit.

GRIBAUDI, Maurizio. Le savoir des relations: liens et racines sociales d'une administration dans la France du XIXe siècle. Le mouvement social, juillet-septembre, 2009. épocas. ${ }^{67}$ Ahora bien, la pregunta siguiente debería ser: ¿Es posible extender este paradigma familiar hacia los funcionarios pertenecientes a sectores de menor peso social? La respuesta a esta cuestión es compleja, pues ella presupone un minucioso trabajo de fuentes para buscar las conexiones familiares y sociales de aquellos funcionarios que no fundaron familia del prestigio suficiente como para que sus hechos dejaran una impronta en los documentos más usuales y en los estudios genealógicos. Es decir, habría que recurrir a trabajar con los registros parroquiales y otro tipo de documentación, esto solo es posible llevarlo a cabo cuando el universo de casos a tratar es realmente reducido. Si hacerlo para un pequeño pueblo de alrededor de 2.000 habitantes es ya farragoso, prolijo y lleva largo tiempo, intentarlo en una ciudad como Buenos Aires, Santiago de Chile, Santafé de Bogotá o Montevideo de mediados del siglo XIX, que cuentan con varias decenas de miles de habitantes, probablemente sea algo superior a las fuerzas (y quizá, la vida) de un investigador. Sobre todo, porque el tipo de fuentes que nos han llegado hasta nosotros para el estudio de esa cuestión en la América Latina del XIX, no resulta comparable a la que podemos tener para Europa en el mismo periodo. Por ejemplo, Maurizio Gribaudi ha trabajado en Francia con un fondo de cartas de presentación y de legajos sobre carreras individuales de los todos los funcionarios de salud que trabajaron en tres ministerios entre 1803 y $1910 .{ }^{68}$ Hasta ahora, nada parecido hemos hallado en los archivos de los distintos casos nacionales que estamos estudiando y es más, también se interrumpen en general los viejos formularios de fojas de servicio del periodo colonial, con lo cual perdemos un precioso útil de análisis. Todo esto nos ha dejado con pocas posibilidades, por el momento, de extender hacia los sectores menos pudientes el análisis de las relaciones entre nexos familiares y carrera burocrática durante el siglo XIX.

De todos modos, hay algo que nos parece evidente: si en los últimos tramos del periodo colonial, pese a las limitaciones que imponía el hecho de que una carrera burocrática típica podía comenzar en una ciudad peninsular, pasando más tarde por varias otras, fueran éstas peninsulares o americanas, la presencia de las redes familiares era bien perceptible, qué no ocurriria cuando ya ese tipo de funcionarios imperiales "itinerantes" habia ya desaparecido. Desde la ruptura independentista, en efecto, la movilidad espacial fue casi inexistente, con lo cual, es establecimiento de vínculos familiares en el medio social en donde se desempeñaban las funciones era algo obvio y no tenía, según lo que sabemos hasta ahora, ningún tipo de limitación. Es decir, no nos parece una hipótesis aventurada imaginar que durante el periodo independiente, este fenómeno del peso de las relaciones familiares en la carrera de un funcionario hubiera sido aún más importante que en la etapa precedente. En el caso del Ecuador, existe además otro aspecto que le es peculiar y que refuerza la necesidad de estar inmerso en una red social de cierta relevancia, pues los candidatos a funcionarios de Hacienda están obligados a presentar una garantía hipotecaria para acceder al puesto. Esta obligación, como parece obvio señalar, no hace más que reforzar las relaciones entre el aspirante a un empleo y sus redes sociales.

La burocracia de una época a la otra: ¿continuidad o ruptura? Hay decenas de ejemplos puntuales, como los de la familia Portales en Chile que tienen cuatro generaciones de servidores del poder colonial y después, republicano, desde el siglo XVII hasta mediados del XIX, de los Lessaga en la provincia de Santa Fe del Río de la Plata, que traspasaron también un largo 
69

GARAVAGLIA, Juan Carlos. La burocracia en el Río de la Plata... Op. Cit.

70

ARNOLD, Linda. Op. Cit.
71

WILDE, Eduardo. [1872]. La carta de recomendación. En: Obras completas. Buenos Aires: La Facultad, 1935. siglo desde mediados del XVIII hasta los años sesenta del XIX o los Acuña de Figueroa en el Uruguay, que trabajaron en dependencias de Hacienda durante la colonia, pasando luego sin problemas por las administraciones porteña y artiguista, la Cisplatina y el Estado Oriental. Para Buenos Aires, hemos podido responder, parcialmente, a esta pregunta. ${ }^{69}$ En ese caso, nos hallamos ante una cierta imagen de continuidad, de al menos un tercio de los empleados en los sectores medios y bajos de la administración estatal, pero eso sí, con algunos cambios en la estructuración de las oficinas y las reparticiones. Mas, es muy difícil, con los documentos que han llegado hasta nosotros, tener una certeza completa sobre este asunto. Señalemos que el estudio de Linda Arnold sobre México entre 1742 y 1835, muestra un panorama similar. ${ }^{70}$ Pero, es muy difícil, con los documentos que han llegado hasta nosotros, tener una certeza completa sobre este asunto. De todos modos, lo que parece claro en todos los ejemplos que hemos estudiado, es que fue justamente en el área de Hacienda donde fue mayor la estabilidad de los funcionarios entre las dos épocas que hemos estudiado. Esto es algo que debe ser relacionado de manera directa con la necesidad evidente de poseer una cierta formación para integrar una oficina en esta área tan sensible de la construcción estatal; pues, como ya lo hemos dicho varias veces, la fiscalidad constituye el corazón del proceso de formación de los nuevos estados, tanto en experiencia europea como en la de las Américas.

\section{Funcionarios, empleados y "empleomanía"}

Ahora bien, más allá de los lazos familiares y con frecuencia, como continuación de ellos, se encuentran los nexos anudados a través de las redes sociales en las que se hallan inmersos todos los individuos. Es aqui donde juegan un papel fundamental las amistades, las relaciones, las recomendaciones. El argentino Eduardo Wilde, en un texto de 1872 "La carta de recomendación", escribió unas pocas líneas de introducción que vale la pena citar aquí:

\begin{abstract}
Un buen acomodo quiere decir en castellano, un empleo en el cual se trabaje poco y se gane mucho. De aqui la ingente suma de pretendientes que tiene cada puesto vacante. Para alcanzar un empleo se necesita empeño, buenas relaciones. Cualquiera diría que para ocupar un puesto se necesita aptitud, pero esto que parece verdad a primera vista, es un sofisma en Buenos Aires. Las aptitudes son las cualidades en que menos se piensa. El favor, la recomendación y la condescendencia, germinan de un modo alarmante y han dejado enfermiza a esta sociedad. Verdaderamente, en Buenos Aires, el valor del mérito ha desaparecido o se ha desvirtuado. Tener amigos (iquién no tiene amigos en un país en que todos somos iguales!) es la mayor de las ventajas. Los puestos en que se gana dinero circulan en un grupo de amigos. ${ }^{71}$
\end{abstract}

Esto parece un eco de algunas cosas que decía la Memoria de hacienda neogranadina de 1843 :

Descendientes de un pueblo en que la empleomanía ha sido y es una enfermedad, buscamos en los empleos, no una ocupación productiva, sino un medio holgado de subsistir. De aquí la pereza, la indolencia en el servicio publico. Los empleados son una especie de sine cura a que todos nos creemos con derecho, y en cuyo desempeño el cobro del sueldo es la mas importante función.

Y agrega un poco más adelante:

El Gobierno se ve molestado y hostigado por un enjambre de necios pretendientes que sin la menor modestia hacen valer méritos y capacidades que no tienen, y cuando 
Memoria del Secretario de Hacienda de Nueva Granada al Congreso Constitucional de 1843. Bogotá: Imprenta de J. A. Cualla, 1843.
Fuentes: Guatemala: ZARAZÚA, Juan Carlos, Op. Cit.; Colombia: LÓPEZ BEJARANO, Pilar, Op. Cit.; Chile: LÓPEZ TAVERNE, Op. Cit.; Ecuador: VELASCO HERRERA, Viviana, Op. Cit.; Costa Rica: RODRIGUEZ SOLANO, Pablo, Op. Cit.; Brasil: CARVALHO, José Murilo de. A construção da ordem Rio de Janeiro: Civilização Brasileira, 2006: Buenos Aires: AGN, Buenos Aires, X-12-3-15. provee los cargos, se gana tantos enemigos cuantos han sido los excluidos en las provisiones, y el nombrado o es ingrato o se hace egoísta para no perder el empleo. ${ }^{72}$

En fin, dadas las características de la organización burocrática del periodo colonial, pese a los intentos de la Corona de reformarlo hacia fines del XVIII, no es casual que los nuevos ciudadanos piensen su relación con los empleos del estado a través de este particular cristal.

Veamos más de cerca este tema de la "empleomanía", el cuadro siguiente nos muestra los datos que hemos podido recolectar para dar cifras sobre la cantidad de burócratas del Estado por cada mil habitantes. Por supuesto, hay aquí innumerables problemas - desde la limitada fiabilidad de las cifras de población, hasta la cuestión de los límites en cuanto al tipo de empleos seleccionados. Nosotros hemos decidido tomar en cuenta solamente a los burócratas que trabajan con el Estado central, o sea, sin incluir a los empleados de las provincias (o departamentos, según sea el país), como tampoco hemos contabilizado a los que trabajan en las municipalidades. Y se trata siempre de "oficinistas", excluimos resguardos aduaneros, guardias nocturnos y todo otro personal asimilable a algún cuerpo armado.

Cuadro 8: Número de empleados cada mil habitantes ${ }^{73}$

\begin{tabular}{|l|c|c|}
\hline País & Año & \\
\hline Estado de Guatemala & 1837 & 0.3 \\
\hline Colombia & 1843 & 0.6 \\
\hline Chile & 1854 & 0,7 \\
\hline Ecuador & 1839 & 0.7 \\
\hline Costa Rica & 1848 & 0.9 \\
\hline Imperio del Brasil & 1877 & 2.6 \\
\hline Estado de Buenos Aires & 1861 & 2.7 \\
\hline
\end{tabular}

Como se puede ver, comparando nuestros datos con los de Murilo de Carvalho para el Brasil, quien discute en su trabajo la conocida frase de Joaquim Nabuco [1883] sobre la burocracia imperial "a burocracia era a vocação de todos" ${ }_{14}$ no parece que la crítica a la "empleomanía" esté fundada en datos reales. Pero, no olvidemos que, a veces, estas comparaciones cuantitativas - tan queridas por algunos economistas y sociólogos - son muy engañosas. Pues la percepción popular sobre este fenómeno, proviene en general de los medios urbanos, donde justamente abundan los burócratas. Al contrastarlos con la entera población de un estado independiente (en una época en que la mayor parte de la población era rural), estamos escamoteando una parte esencial de la cuestión que es, como decíamos, el fenómeno de la percepción de los citadinos sobre este asunto, pues ¿cuántas veces habrá visto un oficinista un indio guatemalteco o ecuatoriano en aquellos años? En el caso del Estado de Buenos Aires (que se destaca con las cifras más elevadas), en 1861, la relación de burócratas cada mil habitantes se multiplicaría por tres, si tomáramos exclusivamente a la población urbana como punto de referencia. Por otra parte, un vecino de la campaña de Buenos Aires sabe muy bien quiénes son el cura párroco o el juez de paz, pero éstos no cobran un verdadero salario y por lo tanto, no lo hemos tomado en cuenta en el cuadro... Como decíamos antes, este indicador tiene sus bemoles.

De nuestros estudios surge también otra forma de mirar los nexos entre grupos familiares, redes sociales, amistades y funcionarios del estado. 
75

GAUTREAU, Pierre y GARAVAGLIA, Juan

Carlos. Inventando un nuevo saber estatal sobre el territorio: la definición de prácticas, comportamientos y agentes en las instituciones topográficas de Buenos Aires, 1824-1864. In: Idem (eds.). Mensurar la tierra, controlar el territorio. América Latina, siglos XVIII- XIX Rosario: Editorial Prohistoria/State Building in Latin América, 2011.
Nada dice que el hecho de ser "alguien conocido" sea efectivamente una desventaja en cuanto a la calidad del trabajo que ese candidato deberá desempeñar, pues justamente, por ser "conocido", tienen el voto de confianza que le otorga los antecedentes de sus parientes y la posibilidad, para el empleador, de acudir a éstos si el funcionario olvida en demasía sus obligaciones. En esta sociedad ibérica en la cual las redes familiares juegan un papel central en la configuración de las relaciones sociales, esta situación no debería asombrarnos. Estamos, es cierto bien lejos de Weber. Considerar a la burocracia como un aparato, tal como se repite una y otra vez en muchos estudios sobre esta cuestión en América Latina, es algo totalmente fuera de lugar, no hay aquí ningún aparato, hay un entramado de relaciones sociales en el cual los vínculos parentales son, con frecuencia, un parámetro central.

Pero así mismo, no hay dudas en que hay varias áreas de trabajo en las oficinas en las cuales es imprescindible poseer una formación y aptitudes profesionales adecuadas a la función; nadie trabaja en el Departamento de Topografía y en las mensuras de terrenos sin saber delinear o ser ingeniero tal como lo hemos mostrado en otro estudio ${ }^{75}$ como tampoco, no es fácil ser profesor de la Universidad o contador de Hacienda sin los conocimientos y preparación necesarios...

\section{A modo de conclusión: dudas, interrogaciones y cuentas pendientes} Todo a lo largo de este texto se habla de "funcionarios", "empleados", como de "empleos" y "salarios", "sueldos", etc. Estas son las diversas denominaciones que las fuentes utilizan y no siempre está claro, en cada caso estudiado, cuales son las diferencias concretas entre esas denominaciones. Nosotros consideramos que casi todo individuo que cobra un estipendio del estado entra dentro de nuestro área de interés, sea un empleado civil - se llame o no funcionario - sea un miembro de las fuerzas armadas o de los diversos y variados cuerpos de vigilancia (policía urbana y rural, serenos nocturnos, guardas de aduana, etc.). Nuestros cuadros abarcan desde oficiales mayores de los ministerios - el empleado que se halla inmediatamente debajo del ministro, quien no siempre es un funcionario estable - hasta el último de los porteros - no hay que olvidar que éstos con frecuencia poseen la "Ilave mágica" de acceso a los arcanos de su repartición. No se incluyen en los cuadros a los diputados, los representantes, los senadores, etc., es decir a los miembros pertenecientes sectores políticos o grupos de presión que ejercen en forma temporal la representación de quienes ejercen el derecho de ciudadanía. Por supuesto, con frecuencia hay categorias, como las de los peones de acarreo de las aduanas y receptorías, cuyo número exacto no siempre es accesible y lo hemos señalado en los cuadros para advertencia del lector (de todos modos, éstos, si bien cobran un jornal, no los hemos tomado como funcionarios y por eso decimos más arriba casi todo individuo que cobra un estipendio del estado).

Pero, hay que recordar también - y el ejemplo del Estado Oriental es casi limite en este sentido - que existe una burocracia "paralela" que acompaña a la burocracia formal, pero que está relacionada con la percepción de una serie de impuestos arrendados (los monopolios y estancos, las alcabalas, pontazgos, etc.). Y esa "burocracia en las sombras" se relaciona con impuestos que son, con frecuencia (Nueva Granada, Ecuador, América Central, Chile), una parte sustancial de los ingresos fiscales hasta fines del periodo que estamos considerando. Otro aspecto de sumo interés es verificar como, en algunos ejemplos (Costa Rica y la Nueva Granada), hay oficinas - en 
ANNINO, Antonio. Cádiz y la revolución territorial de los pueblos mexicanos 1812-1821. En: Idem (coord.) Historia de las elecciones en Iberoamérica, siglo XIX. México: Fondo de Cultura Económica, 1995.

77

ACOSTA RODRÍGUEZ, Antonio. Sociedad y haciendas municipales en El Salvador a mediados del siglo XIX. En: GARCÍA JORDÁN, Pilar (ed.). Dinámicas de poder local en América Latina, siglos XIX-XXI. Barcelona: Publicacions i Edicions de la Universitat de Barcelona, 2009.
Recebido para publicação em janeiro de 2012 Aprovado em janeiro de 2012 estos dos casos son la Renta de Tabacos y el Correo, respectivamente - que cumplen de cierta manera una función de columna vertebral para el resto de la burocracia estatal, constituyen su "modelo" de desarrollo en el futuro.

¿Cuáles serian entonces, las conclusiones principales a las que hemos llegado sobre este tema? Primero, en un marco de cierta continuidad en los sectores medios y bajos de la administración - especialmente visible en el caso de los funcionarios de Hacienda - los cambios en la burocracia durante este primer periodo se refieren sobre todo, a un aspecto estructural: re orientar la administración y sobre todo, la fiscalidad, hacia el objetivo de la construcción de un Estado/Nación, abandonando ese lugar de pequeña rama del gran Imperio Hispánico. Segundo: los números con que contamos muestras la existencia de una delgada burocracia al lado de una mayoria aplastante de fuerzas de guerra y de represión; en efecto, del $80 \%$ al 90\% de los individuos que reciben un sueldo estatal se incluyen en esos dos rubros. Esto parece normal, dadas las necesidades de un creciente monopolio de la fuerza en momentos en que están "fallando" algunos de los antiguos componentes de la dominación simbólica imperantes en el periodo precedente. La construcción de los nuevos componentes de esa dominación llevaría su tiempo y era imposible "hacer todo a la vez", dadas los limitados recurso fiscales con que se contaba. La disyuntiva era de hierro: si había que pagar cañones, no se podían construir escuelas.

Un tema que deberá ser tratado en el futuro, es el de los municipios y alcaldías. En efecto, salvo una que otra excepción, los materiales con que estamos trabajando en esta instancia de la investigación, no nos permiten observar una parte sustancial del proceso de construcción estatal que resulta ocultado a nuestros ojos cuando utilizamos las memorias y los documentos producidos a nivel estatal. Es decir, los ayuntamientos y alcaldias - que tienen en muchos casos un papel bastante relevante en la policia urbana, la higiene, las obras públicas e incluso, en la educación - no están incluidos por ahora en nuestro estudio. Y no debemos pasar por alto el hecho de que, para todas aquellas experiencias en las que las decisiones tomadas en Cádiz tuvieron influencia (México ${ }^{76}$ y las repúblicas centroamericanas son ejemplos muy evidentes, ver, por ejemplo, el caso de El Salvador ${ }^{77}$ ) el papel de los ayuntamientos "constitucionales" heredados de la carta gaditana de 1812, fue de gran importancia. Esta es una asignatura pendiente y en etapas posteriores de nuestra investigación estaremos obligados a tomar en cuenta este hecho.

Asimismo, en nuestro trabajo mencionamos en forma muy rápida a algunos individuos que ejercen funciones relacionadas con la construcción estatal, sin tener ni un sueldo del estado, ni un verdadero estatuto de funcionarios: escribanos, agrimensores, agentes de cambio, etc., pero, en general, en esta etapa no nos hemos casi ocupado de ellos. También habrá que ocuparse en el futuro del papel de estos individuos. Y hay otra categoria muy especial, la compuesta por los eclesiásticos que, a no dudar cumplen también funciones relacionadas estrechamente con la construcción estatal. Hasta que no se dicten los códigos civiles, en una parte sustancial del derecho de familia estará en manos de la jurisdicción eclesiástica, así como el control de los libros de bautismos, matrimonios y defunciones. La educación también es un lugar privilegiado en el cual los eclesiásticos ocupan un lugar especial, como en todo el orbe católico durante esa época. Y en muchos ámbitos, la voz de sacerdotes y curas será la impulsora de procesos que terminan finalmente en la justicia civil, como es el caso de la persecución de los "amancebados", "vagos" y "malentretenidos". Pero, todo esto será examinado en el momento en que tratemos el tema de la justicia, elemento esencial en el camino de la construcción del estado. 